\title{
Constitucionalização da Atividade de Inteligência - Perspectivas e Desafios Brasileiros
}

\section{Gibran Ayupe Mota}

Docente do Programa de Mestrado em Segurança Pública - Universidade Vila Velho - Vila Velha/ES e da Escola de Inteligêncio ABIN/PR. Mestre em Segurança Pública pela Universidade Vila Velha (UVV).

\section{Henrique Geaquinto Herkenhoff}

Docente do Programa de Mestrado em Segurança Pública e da Graduação em Direito - Universidade Vila Velha - Vila Velha/ES. Doutor em Direito Civil (USP).

\section{Pablo Silva Lira}

Docente do Programa de Mestrado em Segurança Pública - Universidade Vila Velho - Vila Velha/ES. Doutorando no Programa de Pós-graduação em Geografio (UFES). Coordenador do Núcleo Vitório do INCT Observatório das Metrópoles.

\section{Erika da Silva Ferrão}

Docente do Programa de Mestrado em Segurança Pública e da Graduação em Psicologia- Universidade Vila Velha - Vila Velha/ES. Doutora em Psicologio (UFES/SDSU-EUA). Membro de grupos do Diretório de Pesquisa do CNPq (Pesquisas em Psicologia Pediátrico/USP-Ribeirõo Preto; Processos Psicológicos e Saúde/UFES).

\begin{abstract}
Data de recebimento: $18 / 02 / 2018$
Data de aprovação: 03/08/2018

Dol: 10.31060/rbsp.2018.v12.n1.912
\end{abstract}

\section{Resumo}

No contexto histórico brasileiro, em razõo de conjunturas passadas por vezes fomentada por determinados setores da mídio e grupos políticos, a Inteligêncio de Estado se ressente da ousência de uma política pública consistente para a óreo. Dentre os reflexos desse abandono, destaco-se a insuficiente regulamentação legislativa, entendida como necessário ò implementação de formas de controle e à atribuição de prerrogativas para essa atividade pública, cuja missão precípua resume-se em contribuir, com informações, para os processos decisórios que visam à integridade da sociedade e do Estado brosileiros. Neste contexto, buscou-se, por meio de uma revisõo temótico do literatura e registros existentes sobre o tema, investigar e refletir sobre a inserçõo da atividade de Inteligêncio no Constituição Federal Brasileira, sob os prismas da legalidade e legitimidade, tal como ocorre com as áreas da Defesa e da Segurança Pública. De acordo com a pesquisa, constatou-se o quão carente de regulamentaçõo encontra-se a atividade de Inteligência no Brasil, redundando no risco de graves violações a princípios republicanos, dentre eles o da eficiêncio e do controle.

Palavras-Chave

Constituição Federal. Informaçõo (Intelligence). Prerrogativas e Controle. 


\section{Abstract}

Constitutionalization of the Intelligence Acivity - Brazilian Perspectives and Challenge

In the Brazilian historic context, due to past scenarios many times fostered by certain medio sectors and political groups, State Intelligence resents the absence of a consistent public policy for the area. Among the reflexes of that absence, one can highlight insufficient regulatory legislation, that being the necessary implementation of control means as well as allocation of prerrogatives to the public activity, whose primary mission is mainly to contribute, with information, to the decision making processes that aim the integrity of the Brazilian society and State. In that context, the aim was, through a review of literature and existing reports, to investigate and reflect over the insertion of the Intelligence activity in the Federal Consitution of Brazil, under the light legality and legitimacy, as it happens in the Public Defense and Safety areas. According to the research, it was determined how so very legislation deprived is the Intelligence activity in Brozil, jeopardizing republican principles, effiency and control among others.

\section{Keywords}

Federal Constitution. Intelligence. Control and prerrogatives. 


\section{INTRODUÇÃO}

$\triangle$ partir da deposiçáo do presidente Joáo Brasil passou por sucessivos governos militares, somente retornando à democracia no final dos anos 80 . Não havia sido o primeiro movimento de "sístoles e diástoles", como denominara o General Golbery do Couto e Silva, que o país experimentava. $\mathrm{O}$ fato novo nesta oportunidade foi a duraçáo do governo militar (PERALVA, 2000) e, principalmente, o longo período de distensão, que já vinha ocorrendo desde o Governo do General Ernesto Geisel, bem antes da anistia política que, em 1979, inaugurou formalmente o processo institucional de reabertura. A partir deste marco histórico, sucederam-se a eleiçáo, ainda indireta, do primeiro presidente civil, a promulgaçáo da Constituiçáo da República Federativa do Brasil de 1988 (CF/88) e a primeira eleiçáo direta para presidente da República em 1989.

Esse distendido processo de redemocratizaçáo, "lento e gradual" conforme consignado na História, espraiou seus efeitos em todos os segmentos da sociedade brasileira, o que redundou em expressivo consenso acerca da necessidade de ampla reforma do ordenamento jurídico brasileiro, por meio da convocaçáo de uma Assem- bleia Constituinte, 1987-1988. Sendo assim, a CF/88 recebeu a alcunha de "Constituiçáa Cidadă”, como clara referência aos avanços conquistados em matéria de direitos civis, políticos e sociais (BARBOSA, 2016).

Permeada de processos complexos e demandas dos mais variados matizes ideológicos, a Assembleia Nacional Constituinte foi convocada por meio da Emenda Constitucional n. 26 de 27 de novembro de 1985, que determinava a conversão temporária do Congresso Nacional em assembleia nacional constituinte, a inaugurar seus trabalhos a partir de 1 de janeiro de 1987 (BARBOSA, 2016).

A partir do advento da Nova Constituiçáo - enquanto base da estrutura normativa e pressuposto de validade de todo o ordenamento jurídico pátrio (KELSEN, 2006) -, em maior ou menor grau, houve profundas alteraçóes na arquitetura, finalidades precípuas, prerrogativas e deveres das instituiçóes públicas no Brasil.

Sob este diapasáo, houve por bem aos legisladores constituintes, a título de exemplo, a inédita opçáo enquanto política legislativa de "constitucionalizar" a Segurança Pública' que, a partir 
da promulgaçáo da $\mathrm{CF} / 88$, passa a ter previsáo normativa expressa em seu artigo 144. Esta relevante temática cada vez mais presente na pauta de políticas públicas brasileiras, até entáo, contara táo somente com mençóes indiretas nas Constituiçōes pretéritas (SOUZA NETO, 2007).

As Forças Armadas, por sua vez, enquanto protagonistas da Defesa Nacional, foram minuciosamente regulamentadas na Constituiçáo Federal de 1988, considerado o paradigma acerca do que se concebe enquanto normas constitucionais materiais. Conforme se constata do Capítulo III, no artigo 142, por meio de três parágrafos e dez incisos, a Carta Magna desceu, por exemplo, ao detalhe de prescrever normas acerca do uso de uniformes por parte dos militares, enquanto prerrogativa das patentes (BRASIL, 1988).

É consabido que governantes, ao se depararem com temas afetos à segurança nacional, tendem a justificar institucionalmente e a delimitar as funçōes das forças armadas, das polícias e dos serviços de Inteligência, com lastro na clássica concepçáo que estes três ramos de atividades estatais caminham conjunta e complementarmente (CEPIK, 2003).

Neste ponto, inexoravelmente, ressoa a seguinte questão: por qual razão a milenar e a cada dia mais relevante atividade de Inteligência - partindo do pressuposto de estarmos inseridos na "sociedade do conhecimento" - não ter seus contornos minimamente delineados na entấo novel Constituição? Mais relevante talvez: quais os efeitos, sob os prismas republicanos da eficiência e do controle democrático, essa lacuna constitucional referente à Inteligência se fizeram perceber na sociedade brasileira, nas últimas dé- cadas? O presente trabalho visa lançar luzes sobre esses questionamentos, inquietantes àqueles que se dedicam à pesquisa e à análise da coisa-pública no Brasil.

Há pouca literatura nacional sobre o tema da Inteligência e menos ainda quando se trata especificamente da sua normatizaçáo e controle, ao passo que os autores internacionais náo se ocupam de questôes especáficas do cenário brasileiro. Ainda assim, a base Scielo contribuiu com alguns artigos correlatos que puderam ser utilizados com proveito.

Nos capítulos a seguir, será traçado inicialmente um resumido histórico da atividade de Inteligência no Brasil e como a associaçáo ao Regime Militar conduziu, de um lado, à sua deslegitimação eà quase extinçáo das suas estruturas quando da redemocratizaçáo e, de outro, a uma regulaçáo jurídica frágil, com sua omissáo no texto da Constituiçáa da República, implicando tanto a falta de instrumental jurídico para a atuaçáo como de mecanismos de controle dos órgáos atualmente responsáveis pela atividade. Após um breve passeio pelas estruturas jurídicas da atividade de Inteligência estrangeiras, conclui-se pela necessidade de refazer um arcabouço jurídico que permita tanto uma atuaçáo efetiva dos serviços de Inteligência quanto o seu efetivo controle, na medida em que legalidade e legitimaçáo, poder e controle andam e devem realmente andar juntos em qualquer Estado democrático que, por outro lado, não deve prescindir de fortes estruturas para assessoramento das decisóes estratégicas e para a elaboraçáo das políticas públicas vetoriais.

\section{Breve Histórico da Atividade de Inteli- gência do Brasil}

Conceitua-se Inteligência de Estado como 
atividade especializada voltada à antecipação de identificação de ameaças e oportunidades, em apoio ao processo decisório no mais alto nível estratégico estatal (SANTOS, 2016).

No mesmo sentido, segue a conceituaçáo oficialmente adotada no âmbito da administração pública brasileira:

A atividade de Inteligência é o exerćcio permanente de açóes especializadas orientadas para a obtençâao de dados, produção e difusăo de conhecimentos, com vistas ao assessoramento de autoridades governamentais, nos respectivos níveis e áreas de atribuiçáo, para o planejamento, a execução e o acompanhamento das políicas de Estado. Engloba, também, a salvaguarda de dados, conhecimentos, áreas, pessoas e meios de interesse da sociedade e do Estado. (CONSELHO CONSULTIVODOSISBIN, 2004).

A atividade de Inteligência é conhecida desde os tempos mais remotos (VEIGA; ZOTES, 2012), originando-se a partir de quatro matrizes básicas históricas: economia, guerra, diplomacia e polícia (CEPIK, 2003).

A consolidação da Inteligência, enquanto atividade componente da burocracia estatal, no entanto, somente se dá a partir do século $\mathrm{XV}$, quando as cidades-estados italianas abriram embaixadas no exterior, das quais os enviados obtinham informaçóes ${ }^{2}$ estratégicas e em cujas bases estabeleceram redes regulares de espionagem de estado (DULLES, 1963).

O emprego da atividade de Inteligência de Estado no Brasil, compreendido como instru- mento de assessoria às decisóes estratégicas do chefe do Poder Executivo, teve início em 1927, durante o governo do Presidente Washington Luís, com a criaçáo do Conselho de Defesa Nacional $(\mathrm{CDN})$, por meio do Decreto $\mathrm{n}^{\circ}$. 17.999, de 29 de novembro daquele ano (BRASIL, 2016).

A partir da inserçáo do Brasil na Segunda Guerra Mundial, a Inteligência de Estado brasileira passa a contar efetivamente com um órgáo próprio, e não apenas com um Conselho instalado ad hoc e sem corpo técnico próprio. Assim, em 1946, por meio do Decreto no. 9.775-A, de 6 de setembro do mesmo ano, criou-se o Serviço Federal de Informaçóes e Contrainformaçóes (Sfici), compreendendo as seçóes de exterior, interior, segurança interna e operaçóes especializadas (BRASIL, 2016).

O contexto político extremamente conturbado do ano de 1964, que culminou com a deposição do Presidente João Goulart, sob a alegação de estreitas vinculaçóes deste com segmentos radicais de esquerda e de colocar em marcha profundas reformas de base que contrariavam o status quo da época, inaugurou o período reconhecido como Governo Militar ou Regime Militar, em março de 1964 (BARBOSA, 2016). Essa conjuntura foi o cenário no qual se deu a criaçáo do Serviço Nacional de Informaçōes (SNI), em 13 de junho de 1964, sob o prumo da Doutrina de Segurança Nacional, gestada na Escola Superior de Guerra (ESG).

O SNI caracterizou-se por sua ligaçáo direta ao Presidente da República e pelo monitoramento de oponentes internos - ou "inimigos internos" -, cujos alvos eram, principalmente, aqueles

2 Informações (intelligence) é um termo especifico e significativo, derivado da informação, informe, fato ou dado que foi selecionado, avaliado, interpretado e, finalmente, expresso de forma tal que evidencie sua importância para determinado problema de política nacional corrente. (PLATT, 1974, p. 30). 
alinhados a ideologias anarquistas e de esquerda. Em 1975, foi instituído o Sistema Nacional de Informaçôes (Sisni), com a missão precípua de integrar os órgáos estatais afetos à Inteligência, a fim de conferir maior operacionalidade à produçáa de conhecimentos julgados estratégicos à época. O SNI era o órgáo que coordenava as açōes do Sisni (BRASIL, 2016).

Apesar da mudança de seus objetivos e métodos a partir da Nova República inaugurada em 1985, o SNI subsistiu até o ano de 1990, quando, em 15 de março, o recém-eleito Presidente Fernando Collor de Melo o extinguiu. A partir de entáo, a atividade de Inteligência de Estado no Brasil deixa de ser exercida por um órgáo diretamente vinculado ao Presidente da República e passa a ser exercida pelo Departamento de Inteligência, subordinado à Secretaria de Assuntos Estratégicos da Presidência da República (SAE/ PR) (BRASIL, 2016).

Por quase uma década, a Inteligência brasileira ficou relegada ao ostracismo, até que, em 1999, por meio da Lei n. 9.883, criou-se a Agênca Brasileira de Inteligência (Abin), bem como regulamentou-se o funcionamento do Sistema Brasileiro de Inteligência (Sisbin).

\section{o Processo de Redemocratização Brasi- leiro e seus Reflexos na Inteligência de Estado}

\section{O Regime Militar e processo de redemo- cratização}

No contexto do processo de redemocratização, sentido no Brasil na década de 1980, conforme mencionado, não houve por parte dos membros da Assembleia Constituinte um compromisso de reestruturaçáo da atividade de Inteligência. Ao contrário, esta estratégica atividade estatal ficou relegada ao ostracismo e à indiferença daqueles que estavam à frente da elaboraçáo e gestáo de políticas públicas até o ano de 1999, quando a Inteligência passou a contar com a normatizaçáo infraconstitucional que culminou com o processo político com a criaçáo da $\mathrm{Abin}^{3}$.

Diante do significativo envolvimento dos órgáos de Inteligência, tanto militares quanto civis, na repressáo aos opositores do regime militar, o SNI era concebido como o núcleo do aparato de informaçôes brasileiro (GONÇALVES, 2008). "Ao contrário do que se costuma pensar em alguns círculos, o SNI nunca se envolveu diretamente-com a repressáo, tortura ou morte de adversários do regime militar durante a ditadura" (FIGUEIREDO, 2005). A partir desse estigma, mesmo decorridas algumas décadas da abertura democrática brasileira, a Inteligência federal ainda é encarada por setores da sociedade com desconfiança e não como um serviço público destinado a contribuir para a segurança e a soberania nacionais.

Mesmo que tardia e infraconstitucionalmente, conforme registra Antunes (2002, p. 09), o governo teve que superar obstáculos em relação à Agência que, criada por força de medida provisória em 1995, apenas foi oficializada por meio de lei em 07 de dezembro de 1999. Ainda segundo Antunes (2002, p. 10), houve resistência por parte da sociedade à sua implantaçáo, sobretudo por setores da imprensa, que acabou por se refletir no Congresso Nacional.

3 A Agêncio Brasileira de Inteligência recebe as atribuições constitucionais de planejar, executar, coordenar, supervisionar e controlar as atividades de inteligência de Estado. Além de uma instituição que executo ações de inteligência e produz conhecimentos para ossessorar o Presidente da República, a Abin supervisiona e controla as atividades desempenhadas por outros órgãos. (SANTOS, 2015, p. 32) 
A Regulamentação da Inteligência Brasileira - Lei n. 9.883/99

Nenhum dos países democráticos e economicamente desenvolvidos prescinde de serviços de Inteligência responsáveis, legais e fortes. A atividade de Inteligência é essencial ao desenvolvimento e preservação dos interesses públicos do Estado Democrático de Direito brasileiro (GONÇALVES, 2008).

Em 1999, com a promulgação da já referida Lei no 9.883-diploma legal que criou a Abin e regulamentou o Sisbin -, uma preocupaçáo que reiteradamente norteou os trabalhos do Congresso Nacional foi a preservaçáo intransigente dos valores democráticos consagrados na $\mathrm{CF} / 88$ (MOTA, 2006).

Neste contexto, a nova fase do constitucionalismo ${ }^{4}$ brasileiro, vigente a partir de 1988, exigiu que se complementassem esforços no sentido de adequar a atividade de Inteligência com o regime democrático (BRASIL, 2016), ora erigido sob o manto do conceito de Estado Democrático de Direito (BRASIL, 1988).

Todo o processo legislativo que deu origem à lei em questáo demonstrou a consolidaçáo, no parlamento, do entendimento de que, sem Inteligência, um país não alcança o status de nação soberana. Associado a este consenso, porém, não mais se concebia soberania sem democracia. A nova onda democrática reclamava da atividade de Inteligência a irrestrita observância aos imperativos da jovem Constituiçáo de 1988, principalmente no que diz respeito aos princípios atinentes à Administraçáo Pública e aos Direitos e Garantias Individuais (MOTA, 2006).

Este compromisso democrático, sob o prumo constitucional da irrestrita observância dos direitos fundamentais e Estado Democrático de Direito, consta expressa e detalhadamente preconizado na Lei de criaçáo da Abin e do Sisbin, logo em seus artigos primeiro e terceiro, conforme segue abaixo:

Art. 1, $₫ 1$ lo O Sistema Brasileiro de Inteligência tem como fundamentos a preservaçáo da soberania nacional, a defesa do Estado Democrático de Direito e a dignidade da pessoa humana, devendo ainda cumprir e preservar os direitos egarantias individuais e demais dispositivos da Constituiçăo Federal, os tratados, convençóes, acordos e ajustes internacionais em que a República Federativa do Brasil seja parte ou signatário, e a legislação ordinária (giifo nosso).

Art. 3o, Parágrafo único. As atividades de inteligência seráo desenvolvidas, no que se refere aos limites de sua extensão e ao uso de técnicas e meios sigilosos, com irrestrita observância dos direitos e garantias individuais, fidelidade às instituiçóes $\mathrm{e}$ aos prinćpios éticos que regem os interesses e a segurança do Estado (grifo nosso).

\footnotetext{
4 o constitucionalismo pode ser visto, em seu nascedouro, como uma aspiração de uma constituição escrito, como modo de estabelecer um mecanismo de dominação legal-racional, como oposição à tradição do medievo, onde era predominante o modo de dominação carismático, ao poder absolutista do rei, próprio da primeira forma de estado moderno. (STRECK, 2002, p. 95) Ainda, paro Corvalho (2009, p. 243), o constitucionalismo "[.... reporta-se a um sistemo normativo, enfeixado na Constituição, e que se encontro acima dos detentores de poder". Por fim, para Bonovides (2011, p. 225) "a Constituição veio a exteriorizar-se, pois, num instrumento escrito, adquirindo aspecto formal. o caráter de rigidez há sido em alguns Estados o seu traço mais simbólico".
} 


\section{Mecanismos de controle da Atividade de Inteligência no Brasil - do Republicano Equilíbrio Entre Eficiência e Controle}

Controle é a "faculdade de vigilância, orientação e correçáo que um Poder, órgáo ou autoridade exerce sobre a conduta funcional do outro" (MEIRELLES, 2015). Em regimes democráticos, o controle da Administraçáo Pública é um pilar fundamental com vistas à implementaçáo da eficiência da máquina estatal, ao incremento da cidadania e, em última instância, à consecução do bem coletivo (BRASIL, 2016).

A Democracia fundamenta-se no direito de cada cidadáo de tomar parte nos assuntos públicos, seja de maneira direta, seja por intermédio de seus representantes eleitos (MEIRELLES, 2015). Se informaçáa é poder eseo poder emana do povo, a informaçáo deve ser acessível a todo o povo - ou ao menos ao Parlamento. Neste sentido Max Weber qualifica um Parlamento como ativo quando, mediante o exercício do direito de pesquisa ou investigaçáo, possa ter acesso a todos os segredos no poder da burocracia (MIGUEL, 2002).

Segundo Gonçalves (2005, p. 20), enquanto o controle envolve um conjunto de parâmetros e limitaçóes legais aos quais deve-se ater a Administração, a fiscalizaçáa refere-se ao legítimo poder de determinadas instituiçóes e autoridades de averiguar o cumprimento das atribuiçóes da Administraçáo em conformidade com o arcabouço jurídico-normativo (GONÇALVES, 2005).

Sob este primado, assim como as demais funções estatais, a atividade de Inteligência está sujeita a mecanismos públicos de controle. Este controle visa a garantir a lisura no cumprimento da Política Nacional de Inteligência (PNI) que, na condição de política pública de governo, há que considerar os princípios constitucionais ex- plícitos e implícitos (BRASIL, 2016).

Controle Ordinário. A Inteligência de Estado está sujeita ao controle externo exercido pelo Congresso Nacional, com o auxílio do Tribunal de Contas da Uniáo (TCU). Este controle consiste na fiscalizaçáa contábil, financeira, orçamentária, operacional e patrimonial, conforme artigos 70, 71 e 72, da Constituiçáo Federal (BRASIL, 1988). No âmbito do controle interno, enquanto controle exercido por ente do mesmo Poder, é responsável pelo controle de gestáo da Inteligência a Secretaria de Controle Interno da Presidência da República (Ciset).

Controle Especifico ou finalistico. O controle acerca da Inteligência Estratégica ou de Estado é, por força de lei, atribuiçáo da Comissáo Mista de Controle das Atividades de Inteligência (CCAI) - comissáo permanente do Congresso Nacional (BRASIL, Lei 9883) - na forma prevista em seu Regimento Interno (Resoluçáo n. 2, de 22 de novembro de 2013, do Congresso Nacional). Para o desempenho de seu papel institucional, a CCAI recebe relatórios gerais, parciais e extraordinários advindos de cada órgão que compóe o Sisbin. Ademais, a CCAI tem a prerrogativa legal de realizar inspeçóes em áreas, documentos e arquivos, sem a restriçáa de acesso decorrente de eventual atribuiçáa de grau de sigilo. Sob a perspectiva de controle finalístico, a atividade de Inteligência de Estado submete-se, ainda, ao controle exercido pela Câmara de Relaçốes Exteriores e Defesa Nacional (Creden), a qual compete supervisionar a fiel execuçáo da PNI, por parte dos órgãos nacionais integrantes da comunidade de Inteligência Estratégica (BRASIL, 1999).

\section{Constitucionalização da Atividade de In- teligência. Controle e legitimação}

Serviços de Inteligência, em sua acepçáo clássica, são órgãos do Poder Executivo que funcionam assessorando os chefes de Estado e de governo e, dependendo de cada ordenamento 
constitucional, outras autoridades na administraçáo pública e mesmo ao Parlamento (CEPIK, 2003). Portanto, é a Constituiçáo de cada país que, ao versar direta ou indiretamente acerca da atividade de Inteligência, estabelecerá de forma suprema o perfil, limites e prerrogativas desse serviço público. Neste sentido, cumpre-nos registrar o depoimento de Antunes (2001, p.09):

Acredito que a principal discussáo a ser elaborada sobre o vínculo da atividade de Inteligência com o Estado Democrático deve dizer respeito ao grau de constitucionalidade desse serviço, à regulamentaçáo pública e ao conhecimento sobre os órgáos e cargos estatais responsáveis pela conduçáo da atividade de Inteligência no país.

Diante dessas premissas, sobreleva-se a questão fulcral do presente trabalho: a constitucionalizaçáo, ou sob outra terminologia, a positivaçáo constitucional da atividade de Inteligência brasileira teria o condáo de implementar formas aperfeiçoadas de controle democrático e de elevar os padróes de eficiência voltados a essa atividade considerada estratégica em qualquer naçáo próspera e soberana?

Inicialmente, há que se registrar que existem várias acepçóes acerca da palavra "constitucionalização": A primeira delas e, na ambiência dos fins traçados para este artigo, a mais relevante trata-se da "constitucionalizaçáo-inclusão", que é imediata. Determinado assunto, antes tratado pela legislaçáo ordinária, ou simplesmente ignorado, passa a fazer parte do texto constitucional. Também denominada 'constitucionalizaçáo-eleva- çáo', consiste na transferência para a Constituiçáo da sede normativa da regulaçáo de determinada matéria (SOUZA NETO e MENDONÇA, 2006).

Voltando-nos diretamente ao objeto ora em análise, constata-se que a situaçáo da Inteligência brasileira se enquadra perfeitamente na primeira hipótese acima descrita. Isto porque, em toda a extensão do texto constitucional de 1988 , não há atualmente qualquer mençáo à Inteligência na estrutura do Estado Brasileiro, quer como organizaçáo, atividade ou conhecimento (KENT, 1949). Esta temática táo estratégica e cara aos países democráticos e soberanos, no ordenamento jurídico brasileiro, não possui sequer previsão constitucional expressa, sendo matéria regulada por leis ordinárias.

Constituições classificadas como sintéticas limitam-se a prever princípios e normas gerais de regência do Estado, organizando-o e limitando seu poder. De modo oposto, as Constituiçóes analíticas regulamentam toda gama de assuntos entendidos como relevantes ao funcionamento do Estado - a exemplo da CF/88 (MORAES, 2003). A partir dessa dassificaçáo, salta aos olhos que, mesmo que nossa Constituiçáo Federal se enquadrasse na modalidade de uma Constituiçáo sintética, deveria prever em seu corpo a atividade de Inteligência de Estado, estruturando-a e limitando sua atuaçáo com vistas à preservaçáo dos direitos fundamentais de seus cidadãos. Não é compreensível nossa prolixa $\mathrm{CF} / 88$ descer ao detalhe de prever que o "Colégio Pedro II, localizado na cidade do Rio de Janeiro, será mantido na órbita federal", dentre outras regulamentaçóes

5 Sarmento (2012, P. 98) entende hover, além da constitucionalização-indusõo, a constitucionalização-releitura, as quais define do seguinte forma: "A constitucionalização-indusão consiste no tratamento pela constituição de temas que ontes eram disciplinados pela legislação ordinário ou mesmo ignorados. No Constituição de 88, este é um fenômeno generalizado, tendo em visto a inserção no texto constitucional de uma enorme variedade de ossuntos - alguns deles desprovidos de maior relevôncio. Já a constitucionalização releitura liga-se à impregnação de todo o ordenamento pelos valores constitucionais" 
de somenos importância estrutural ao País, porém ignorar por completo a Inteligência de Estado (BRASIL, 1988).

Além da função regulamentadora, a norma constitucional confere à matéria nela veiculada significativo grau de legitimidade perante a sociedade. Ainda segundo Moraes (2003, p. 4), as normas constitucionais conferem aos institutos por ela regulamentados elevado grau de legitimidade: primeiramente, pelo fato de, na condição de resultado de um processo legislativo regular, ser elaborada por parlamentares legitimamente escolhidos pelo povo; em segundo, por se tratar, em Estados laicos, de norma fundamental do ordenamento jurídico, conforme a clássica liçáo de Hans Kelsen (2006, p. 387). Em irretocável síntese, consigna Barroso (2014, p. 92): "com a promulgaçáo da Constituiçáo, a soberania popular se converte em supremacia constitucional".

A legislação, além do mister regulamentador, pode assumir funçáo adicional de implementara confiança dos cidadáos em instituiçóes públicas - o que se convencionou denominar "legislaçáo simbólica" (NEVES, 2011). Acerca dos efeitos regulatórios e simbólicos ${ }^{6}$ decorrentes da previsáo expressa pela Constituiçáo referente à determinada temática pública, bastante ilustrativo o depoimento que se segue acerca da constitucionalizaçáo da Segurança Pública, mas que se aplica perfeitamente à seara da Inteligência:

A constitucionalizaçáo traz importantes consequências para a legitimação da atuaçấo estatal na formulaçáo e na execuçáo de políticas de segurança. As leis sobre segurança, nos três planos federativos de governo, devem estar em conformidade com a Constituição Federal, assim como as respectivas estruturas administrativas e as próprias açóes concretas das autoridades policiais. O fundamento último de uma diligência investigatória ou de uma açáo de policiamento ostensivo é o que dispóe a Constituiçáo. E o é não apenas no tocante ao art. 144, que concerne especificamente à segurança pública, mas também no que se refere ao todo do sistema constitucional (SOUZA NETO, p. 03, 2007).

Um segundo e coexistente paradigma de constitucionalidade, segundo o mesmo autor, trata da observância dos princípios constitucionais e da observância dos direitos e garantias fundamentais, conforme reiterado abaixo:

Devem ser especialmente observados os princípios constitucionais fundamentais - a república, a democracia, o estado de direito, a cidadania, a dignidade da pessoa humana-, bem como os direitos fundamentais - a vida, a liberdade, a igualdade, a segurança. $\mathrm{O}$ art. 144 deve ser interpretado de acordo com o núdeo axiológico do sistema constitucional, em que se situam esses princípios fundamentais - o que tem grande importância, como se observará, para a formulação de um conceito constitucionalmente adequado de segurança pública” (SOUZA NETO, p. 03, 2007).

Neste ponto, é notório que a subsunçáo da atividade de Inteligência no Brasil à Constituiçáo Federal opera-se conforme o modelo acima. Em que pese náo ter sido acolhida expressamente pelo constituinte, trata-se de atividade constitucional, na medida que sua lei ordinária regulamentadora preconiza expressamente, conforme pontuado alhures, o dever de "cumprir e preser-

\footnotetext{
6 As legislações simbólicas, oo se prestaram a uma função política-ideológica, trozem a lume a discussão da autonomia operacional do direito na concepção da Teoria dos Sistemas de Niklos Luhmann, ou seja, da dicotomia entre a autopoiese, que é outoreprodução de um sistema por meio de seu código-diferença e a alopoiese, que é perda dessa capacidade. (OLIVEIRA, 2017)
} 
var a defesa do Estado Democrático de Direito e a dignidade da pessoa humana, devendo ainda cumprir e preservar os direitos e garantias individuais e demais dispositivos da Constituiçáo Federal [...]" (BRASIL, 1999). Trata-se de uma atividade constitucional, porém não constitucionalizada.

Miguel (2002, p.25), ao analisar o regime jurídico dos diversos serviços denominados serviços de Inteligência, espionagem ou de informaçôes, sustenta a tese que "o Estado constitucional, enquanto Estado e enquanto constitucional, necessariamente tem que preservar uma série de áreas reservadas ao acesso irrestrito da populaçáo".

Dentre os serviços de Inteligência historicamente destacados por suas capacidades operacionais e, ao mesmo tempo, por implementarem efetivos mecanismos de controle democrático, cumpre evidenciar os Serviços americanos e os alemães. Como supedâneo da atividade de Inteligência eficiente e controlada, inexoravelmente constata-se a constitucionalizaçáo da Inteligência nesses países.

\section{Estados Unidos da América}

Apesar da Constituiçáa americana não mencionar expressamente seus serviços de Inteligência, as teorias políticas que alimentaram o processo constituinte contemplaram os fundamentos constitucionais aptos a organizar os serviços secretos (MIGUEL, 2002). A partir dessa premissa, a Suprema Corte Americana consolidou o entendimento no sentido que o Poder Legislativo daquele país tem competência universal para regulamentar não somente a atividade de Inteligência, como também para criar, por ato próprio, novas agências a incorporarem sua Intelligence Community (MIGUEL, 2002).

\section{Alemanha}

A República Federal da Alemanha conferiu ao seu serviço federal de Inteligência voltado à defesa da Constituiçáo, o Bundesamt für Verfassungsschutz (BfV), um fundamento constitucional expresso. A partir dessa regulamentaçáo constitucional positivada, os demais serviços de Inteligência alemães foram regulamentados por normas infraconstitucionais, como leis e regulamentos. Como resultado, o ordenamento jurídico alemão oferece, quiçá, as regulamentaçôes mais detalhadas acerca das competências e controle de seus serviços de Inteligência, mantendo perfeitamente discriminadas as competências da Inteligência e da atividade policial (MIGUEL, 2002).

Diante do cenário em que se insere a atividade de Inteligência brasileira, concisamente retratado nestas linhas, percebe-se com dareza solar que esta atividade carece de maiores investimentos em legalidade, justamente a fim de aumentar sua eficiência e, principalmente, a sua legitimidade. Assim sendo, a constitucionalizaçấo dessa milenar e estratégica atividade pública, mesmo que de forma sintética, objetivando táo somente institucionalizar em sede constitucional a Inteligência (em suas reconhecidas matrizes, dentre as quais, Inteligência de Estado, Inteligência de Segurança Pública, Inteligência Militar, Inteligência Fiscal e Inteligência Financeira), ampliando os mecanismos de controle democrático sobre a atividade, figura-se como inadiável política pública em prol da segurança da sociedade e soberania brasileiras. A partir da sustentada previsão constitucional positivada, abre-se azo para a regulamentaçáo mais detida, por meio de Lei Complementar (Lei Orgânica), a fim de prescrever de forma detalhada mecanismos de controles acerca das prerrogativas a serem expressamente regulamentadas.

O quadro comparativo que se segue (WAGNER, 2017), referente às prerrogativas conferidas pelas respectivas legislaçóes aos principais 


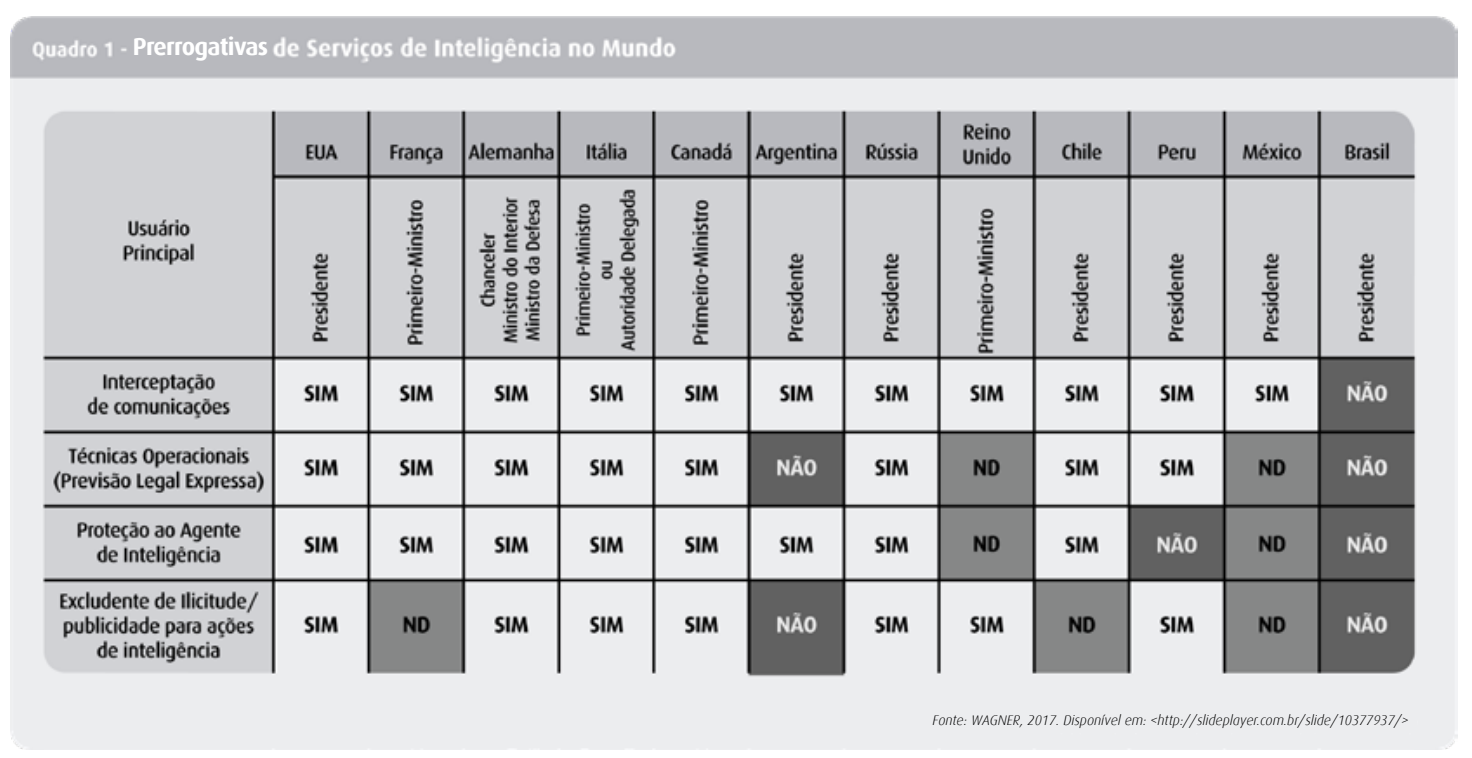

Serviços de Inteligência estrangeiros ilustra, de forma inexorável, a urgência de o Legislativo pátrio deferir a sua Inteligência brasileira os meios legalmente preconizados, afim de que a mesma possa atuar à altura dos desafios que se apresentam ao País.

Salta aos olhos, de forma icônica, como a Inteligência brasileira, se comparada aos principais serviços de Inteligência do mundo, se destaca negativamente no que se refere à atribuiçáo de prerrogativas e de meios técnicos universalmente julgados imprescindíveis ao desempenho de sua relevante missáo de colaborar no processo de elevar o País ao nível das demais naçóes soberanas e prósperas.

É exatamente no sentido de suprir essas lacunas legislativas que, quando presidente $\mathrm{da}$ Comissáo Mista de Controle das Atividades de Inteligência (CCAI), entre 2013 e 2015, o senador Ricardo Ferraço (PSDB-ES) já defendia que uma iniciativa importante para tornar mais efetivo o controle é dar à atividade de Inteligência de Estado status constitucional: "Não há referência na Carta de 1988 à Atividade de Inteligência, aos serviços secretos e a seus mecanismos de controle" (FERRAÇO, 2014). A proposta de emenda à Constituiçáo (PEC) 67/2012, de autoria do senador Fernando Collor (PTB-AL), ora em trâmite no Congresso Nacional, visa ao suprimento dessa lacuna constitucional (BRASIL, 2014).

O Título V da CF/88, em cujo âmbito é proposta a inserçáo de capítulo próprio dedicado à Atividade de Inteligência, enumera as instituiçóes responsáveis pela Defesa (Capítulo II) e pela Segurança Pública (Capítulo III) - resta clarividente a ausência de paralelismo, ao proscrever a Inteligência do texto constitucional. Isso posto, a PEC em comento propugna, pelas razóes resumidamente evidenciadas neste trabalho, pela modificaçáo da redaçáo do art. 144-A, de modo que o Sisbin bem como seu órgáo central, Abin, estejam expressamente previstos na Constituiçáo da República.

Somente por intermédio da elevaçáo da Atividade de Inteligência de Estado ao altiplano constitucional, restará estabelecido um arcabouço normativo mínimo, porém explícito e suficiente, acerca das competências devidas a esta 
atividade típica de Estado, exercida sempre sob o controle e a fiscalizaçáo do Poder Legislativo, consolidando o desenvolvimento de uma cultura de proteçáo aos conhecimentos sensíveis e a busca de oportunidades, em prol da defesa do Estado e de suas instituiçóes democráticas.

\section{Conclusões}

Qualquer país democrático e minimamente competitivo no cenário internacional não pode prescindir de serviços de Inteligência fortes e atuantes. Mais do que nunca, considerando-se o fato de vivenciarmos a denominada "era do conhecimento", o produto obtenível pela atividade de Inteligência - informaçóes estratégicas - ganha relevância inestimável.

No Brasil, em que pese a atividade de Inteligência de Estado ter sido estruturada enquanto instrumento de assessoria às decisóes estratégicas do chefe do Poder Executivo desde 1926 e durante toda sua existência ter desempenhado papel imprescindível ao avanço do País em consolidar-se enquanto nação soberana e próspera, sua imagem, ainda hoje, em alguns setores da sociedade, é associada à episódios repressivos operados por todo o conjunto de órgáos de controle que eram demandados durante o Regime Militar. Urge que o Brasil, sem desconsiderar as liçóes do passado, projete-se rumo à vocaçáo de naçáo próspera e soberana que lhe é devida.

Essa relutânciaé, em parte, compreensível na ambiência da sociologia política: a confiança nas instituiçóes é proporcional à maturidade do contexto político em que estáo inseridas, de maneira que tende a ser muito menor nas democracias recentes que naquelas estabelecidas há mais tempo e de maneira mais estável (RENNÓ, 2001. SILVA e RIBEIRO, 2016. RIBEIRO, 2011), muito mais pela baixa expectativa com relaçáo à sua atuaçáo do que em virtude de uma experiên- cia pessoal negativa concreta com aquele órgáo, afetando negativamente sua capacidade de cumprir suas missóes institucionais e democráticas (DAMMERT, 2014. RIBEIRO, 2011. SANDOVAL, 2011). Ébem verdade que o índice de confiança e a demanda por maior confiabilidade podem facilmente se misturar na cultura coletiva democrática, de maneira que uma populaçáo tende evolutivamente a exigir sempre mais controle e melhores resultados de suas instituiçóes, por mais madura que seja a convivência política (SANTOS e ROCHA, 2011. LOPES, 2004. SCHENEIDER, 2013).

A consequência mais deletéria ao interesse público desse estigma que impregnou a imagem da Inteligência de Estado foi, notadamente nos anos seguintes à reabertura democrática, lançar esta atividade pública nas sendas do ostracismo e da proscriçáo. Uma grave consequência desse processo emerge no fato de a Assembleia Constituinte de 1988 ter ignorado completamente a existência da Inteligência de Estado, redundando, irônica e lamentavelmente, em menos regulamentaçáo da atividade sob a ótica do controle de seus produtos e do emprego de suas prerrogativas. Tal regulamentaçáo coube à Lei n. 9.883 de 1999, diga-se de passagem, de forma bastante lacônica - o que não atende aos princípios constitucionais que gravitam em torno do conceito de Estado Democrático de Direito.

É evidente que, após uma atuaçáo nebulosa durante o Regime Militar, os serviços de Inteligência foram duramente atingidos com a redemocratizaçáo, praticamente extintos e até hoje, em que buscam lentamente se reestruturar, quase inteiramente privados das prerrogativas legais que todos os países democráticos e avançados do planeta asseguram aos seus congêneres, mas também que, ironicamente, foram igualmente relegados a um controle distante e pífio por parte da sociedade a que devem servir e que tanta des- 
confiança lhes reserva.

Diante de todo enredo sucintamente descrito no presente trabalho, constata-se o quáo carente de regulamentaçáo encontra-se a atividade de Inteligência no Brasil, redundando no risco de graves violaçóes a princípios republicanos, dentre eles o da eficiência e do controle. A única maneira de esvanecer as brumas de um passado questionado é estabelecer regras claras e mecanismos eficientes de controle da atividade de Inteligência que permitam, ao mesmo tempo, ferramental jurídico para a atuaçáo das instituiçôes de Inteligência, mas também, ao cidadão, a garantia de que essa atuaçáo será sempre e apenas a serviço do bem comum e da democracia - do que resultaria, aliás, uma garantia essencial para o operador, para o trabalhador do SISBIN: o de não receber demandas ou missóes que afrontem a sua consciência, de não temer por si mesmo ao aceitar uma ordem legal ou recusar uma ilegal, na medida em que essas fronteiras estejam claramente traçadas e haja mecanismos de controle que as assegurem.

\section{Referências Bibliográficas}

ANTUNES, Priscila Carlos Brandão. SNI \& ABIN: Entre a Teoria e a Prática. FGV Editora. Rio de Janeiro, 2001.

BARBOSA, Leonardo Augusto de Andrade. História Constitucional Brasileira: mudança constitucional, autoritarismo e democracia no Brasil pós-64. Brasilia: Câmara dos Deputados: Edições Câmara, 2016.

BARROSO, Luis Roberto. Interpretação Constitucional como Interpretação Específica. In: CANOTILHO, J. J. Gomes. Comentários à Constituição do Brasil. Saraiva/ Almedina. São Paulo, 2014. P 91-96.
A constitucionalizaçáo da Inteligência de Estado brasileira, com redaçáo sucinta que se defende neste trabalho, mostra-se hábil a incrementar significativamente os meios de controle externos, aprimorar a regulamentaçáo de prerrogativas e técnicas passíveis de emprego pelos profissionais de Inteligência, e por fim, promoverá a legitimidade e o apreço público que esta atividade pública, como qualquer outra, merece. Com ela pode iniciar-se um ciclo de ganhos recíprocos (DURAND PONTE, 2006. LANIADO, 2001), no qual a sociedade, à medida em que dispóe de mais e melhores mecanismos de controle sobre essa atividade, deposita maior confiança nas instituiçôes de Inteligência e, consequentemente, oferece-lhe maior colaboraçáo e melhores instrumentos para funcionar, ao longo do tempo, o efetivo exercício desse controle cidadáo e a apresentaçáo dos frutos práticos da atividade de Inteligência retroalimentam o ciclo virtuoso, subsidiando um desenvolvimento constante do Brasil.
BONAVIDES, Paulo. Curso de Direito Constitucional. 26. ed. São Paulo: Malheiros, 2011.

BRASIL. Constituição (1988). Constituição da República Federativa do Brasil. Brasília: Senado Federal: Centro Gráfico, 1988.

Lei ก. 9.883, de 7 de dezembro de 1999. Institui o Sistema Brasileiro de Inteligência, cria a Agência Brasileira de Inteligência, e dá outras providências. Diário Oficial da União. Poder Executivo, Brasília, DF, 8 dez. 1999. 
. Discursos Senado Federal: espionagem cibernética. Disponível em: http://www12.senado.leg.br/ emdiscussao/edicoes/espionagem-cibernetica/realidade-brasileira-sem-cultura-de-inteligencia/congresso-deve-fiscalizar-acoes-do-servico-secreto). Brasília, 2014.

Doutrina Nacional da Atividade de Inteligência: fundamentos doutrinários. - Brasilia: Abin, 2016.

CARVALHO, Kildare Gonçalves. Direito Constitucional. $15^{2}$ ed. Belo Horizonte, Del Rey, 2009.

CEPIK, Marco. Espionagem e Democracia. Rio de Janeiro: Editora FGV, 2003.

CONSELHO CONSULTIVO DO SISBIN. Manual de Inteligência: Doutrina Nacional de Inteligência - Bases Comuns. Brasilia: Agência Brasileira de Inteligência, 2004, 44p, p.12.

DAMMERT, Lucía. La relación entre confianza e inseguridad: el caso de Chile. Rev. Crim., Bogotá, v. 56, n. 1, p. 189-207, Abril 2014. Disponível <http:// www.scielo.org.co/scielo.php?script=sci_arttext\&pi$d=$ S1794-31082014000100010\&lng=en\&nrm=iso>. Acesso em 04 Aug. 2017.

DULLES, A. The Craft of Intelligence. Boulder/London: Westview Encore Edition, 1963.

DURAND PONTE, Víctor Manuel. Confianza y eficacia ciudadana en una sociedad con alta desigualdad. Opin. Publica, Campinas, v. 12, п. 2, p. 277-296, Nov. 2006 . Disponível em <http:// www.scielo.br/scielo.php?script=sci_arttext\&pi$\mathrm{d}=$ =50104-62762006000200003\&lng=encnrm=iso> . Acesso em 04 Aug. 2017. http://dx.doi.org/10.1590/ S0104-62762006000200003.

FIGUEIREDO, Lucas. Ministério do Silêncio. Rio de Janeiro: Record, 2005.

GONÇALVES, Joanisval Brito. Revista Brasileira de Inteligência. Agência Brasileira de Inteligência Vol. 1. Brasilia: Abin, 2005.
GONÇALVES, Joanisval Brito. Sed Quis Custodiet Ipso Custodes? 0 controle da atividade de Inteligência em regimes de-mocráticos: os casos de Brasil e Canadá. Tese de doutorado. Universidade de Brasília, 2008, p. 294.

KELSEN, Hans. Teoria Pura do Direito. Trad. João Baptista Machado. São Paulo: Martins Fontes, 2006.

KENT, Sherman. Strategic Intelligence for American World Policy. Princeton: Princeton University Press, 1949.

LANIADO, Ruthy Nadia. Troca e reciprocidade no campo da cultura política. Soc. estado. Brasilia , v. 16, п. 1-2, p. 222-244, Dec. 2001. Disponível em <http://www.scielo.br/scielo.php?script=sci_arttext\&pid=S0102=69922001000100010-\&lng=en\&nrmiso>. Acesso em 04 Aug. 2017. http://dx.doi. org/10.1590/S0102-69922001000100010.

LOPES, Denise Mercedes Nuñez Nascimento. Para pensar a confiança e a cultura política na América Latina. Opin. Publica, Campinas, v. 10, п. 1, p. 162-187, May 2004 . Disponível em <http:// www.scielo.br/scielo.php?script=sci_arttext\&pid=S0104-62762004000100007\&lng=en\&nrm=iso> . Acesso em 04 Aug. 2017. http://dx.doi.org/10.1590/ S0104-62762004000100007.

MEIRELLES, Hely Lopes. Direito Administrativo Brasileiro. 42ed. São Paulo: Malheiros Editores, 2015.

MIGUEL, Carlos Ruiz. Servicios de Inteligencia y Seguridad Del Estado Constitucional. Madrid: Ed. Tecnos, 2002.

MORAES, Alexandre. Legitimidade da Justiça Constitucional. São Paulo: Atlas, 2003.

MOTA, Gibran Ayupe. Revista Brasileira de Inteligência. Agência Brasileira de Inteligência - Vol. 2, n. 3 (set. 2006) - Brasília: Abin, 2006.

NEVES, Marcelo. A Constitucionalização Simbólica. São Paulo: Martins Fontes, 2011. 
OLIVEIRA, Thaís de Souza Lima. Legislação simbólica e a alopoiese no direito: por uma aproximação de conceitos a partir de Marcelo Neves. Disponível em: $<$ http://publicadireito.com.br/artigos/?cod=783919a58a6cea9b> Acesso em: 26 jul. 2017.

PERALVA, Angelina. Violência e o Paradoxo Brasileiro: democracia. Rio de Janeiro: Paz e Terra, 2000.

PLATT, Washington. Produção de Informações Estratégicas. Rio de Janeiro: Biblioteca do Exército e Livraria Agir Editora, 1974.

RENNÓ, Lucio R. Confiança interpessoal e comportamento político: microfundamentos da teoria do capital social naAmérica Latina, in Opin. Publica vol.7no.1 Campinas 2001 disponível em http://www.scielo.br/ scielo.php?pid=S0104-62762001000100003\&script=sci_arttext).

RIBEIRO, Ednaldo Aparecido. Confiança política na América Latina: evolução recente e determinantes individuais. Rev. Sociol. Polit., Curitiba, v. 19, п. 39, p. 167-182, June 2011. Disponivel em <http:// www.scielo.br/scielo.php?script=sci_arttextøpi$\mathrm{d}=$ =S0104-447820110002000128lng=en\&nrm=iso>. Acesso em 04 Aug. 2017. http://dx.doi.org/10.1590/ S0104-44782011000200012.

SANDOVAL, Mario. La confianza de los jóvenes chilenos y su relación con la cohesión social. Ultima décad., Santiago, v. 19, n. 34, p. 139-165, jun. 2011. Disponivel em <http://www.scielo.d/scielo.php?script=sci_arttext\&pid=S0718=22362011000100008-\&lng=es\&nrmiso>. Acessado em 04 agosto 2017. http://dx.doi. org/10.4067/S0718-22362011000100008.

SANTOS, Jeremias. 0 conhecimento produzido pela atividade de Inteligência a partir da análise criminal como ferramenta acessória: contribuições para ações de segurança pública. 2016. 62f. Dissertação (Mestrado em Segurança Pública) - Universidade Vila Velha, Vila Velha. 2016.
SANTOS, Manoel Leonardo; ROCHA, Enivaldo Carvalho da. Capital social e democracia: a confiança realmente importa? Rev. Sociol. Polit., Curitiba, v. 19, n. 38, p. 43-64, Feb. 2011 . Available from <http:// www.scielo.br/scielo.php?script=sci_arttext\&pid=S0104-44782011000100004\&lng=en\&nrm=iso> . access on 04 Aug. 2017. http://dx.doi.org/10.1590/ s0104-44782011000100004.

SANTOS, Roberto Ferreira dos. $\mathbf{0}$ arcabouço legal da atividade de Inteligência do Brasil: entre a eficiência e o controle. Universidade de Brasilia, 2015. Disponível em: <http://bdm.unb.br/ bitstream/10483/11013/1/2015_RobertoFerreiradosSantos.pdf> Acesso em: 28 jul. 2017.

SARMENTO, Daniel. Direito Constitucional: Teoria, História e Métodos de Trabalho. $1^{\text {a }}$ ed. Belo Horizonte: Fórum, 2012.

SILVA, Geélison Ferreira da; RIBEIRO, Ludmila Mendonça Lopes. Confiança nas instituições democráticas e vitimização por crime: qual a relação? In Rev. Sociol. Polit. vol.24 no.58 Curitiba June 2016 disponível em http://www.scielo.br/scielo.php?script=sci_arttext\&pid=S0104-44782016000200059.

SOUZA NETO, Cláudio Pereira de. A segurança pública na Constituição Federal de 1988: conceituação constitucionalmente adequada, competências federativas e órgãos de execução das políticas. Revista de Direito do Estado, v. 8, p. 19-73, 2007.

SOUZA NETO, Cláudio Pereira de; MENDONÇA, José Vicente Santos de. Fundamentalização e fundamentalismo na interpretação do princípio constitucional da livre iniciativa. A constitucionalização do direito: fundamentos teóricos e aplicações específicas. Rio de Janeiro: Lúmen Juris, 2006.

STRECK, Lenio Luiz. Jurisdição Constitucional e Hermenêutica: Uma Nova Crítica do Direito. Porto Alegre: Livraria do Advogado, 2002. 
VEIGA, Carla Carvalho e ZOTES, Luiz Pérez. Contribuições da Inteligência Competitiva para a Formulação e Implantação da Estratégia. Revista Eletrônica Sistemas \& Gestão. v. 7, n. 4, 2012. p. 628-640. Disponível em <www.uff.br/sg/index.php/sg/article/download/ V7N4A10/V7N4A10>. Acesso em 22 mar. 2017.
WAGNER, TomásXimenes.Disponívelem:https://www. google.com.br/search?safe=off\&biw=1024\&bih=467ধtbm=isch\&sa=18ei=mE0LWqu0L8yUwgSNtpSwBQ\&q=quadro+servi $\%$ C3\%A7os+de+inteligencia+no+mundo+intercepta\%C3\%A7\%C3\%A3080q=quadro+servi\%C3\%A7os+de+inteligencia+no+mundo+intercepta\%C3\%A7\%C3\%A308gs_l=psy-ab.3...88859.95540. $0.96268 .16 .15 .1 .0 .0 .0 .173 .1535 .0 j 11.11 .0 \ldots . .0 . .1 .1 .64$. psy-ab..4.0.0....0.aOkSTpllalo\#imgrc=dKQQhxHCxdXJRoM: Acesso, via internet, em 28 de novembro de 2017. 



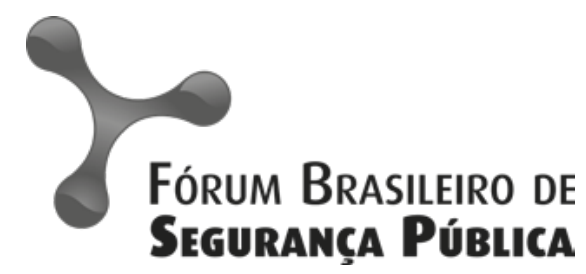

ISSN 1981-1659 